\title{
Effects of Early Resistance Exercises guidelines on Pulmonary Function Measures of Patients with open heart surgery
}

\author{
Tahany Nagy Nagm Eldean1, KaramMosallamEisa2,Mona Aly Mohamed3, Asmaa AlyMahgoub4. \\ 1-Demonstrator in Critical Care and Emergency Nursing Department Faculty of Nursing, South Valley University, \\ Qena, Egypt. \\ 2- Professor of Cardiothoracic Surgery -Faculty of Medicine-South Valley University Egypt. \\ 3- Assistant Professor of Critical care and Emergency Nursing, Faculty of Nursing, Assiut University, Egypt. \\ 4- Lecturer of Critical Care and Emergency Nursing, Faculty of Nursing, Assiut University, Egypt.
}

\begin{abstract}
Background :Open heart surgery is one of the most important procedures that can resolve many cardiac problems. The most important of which are myocardial revascularization, valve replacement or repair of congenital or acquired structural abnormalities, exercise therapy play vital role in preventing the complication after cardiac surgery and other type of surgery especially pulmonary complication. The aim of this study is: To investigate effects of early resistance exercises guidelines on pulmonary function measures of patients With open heart surgery. Research design: A quasi-experimental design was utilized in the present study. The study was carried out at the Cardio Thoracic intensive care unit at South valley University Hospital' A convenient sample of 60 adult p.ts with open heart surgery from both sex assigned in to equal groups (control and study groups). resistance exercise apply 30 minutes, twice a day in the intensive care unit (ICU) until hospital discharge are done through using the three tools(patient assessment sheet, pulmonary function measures and Borg scale. Results: It was revealed that there was an obvious increase in the pulmonary function measures of patients with open heart surgery in postoperative phase compared with preoperative phase, with a very highly significant difference $(\mathrm{p}<0.001)$. Conclusion: The resistance exercise guidelines had a significant impact on Pulmonary Function Measures of Patients With open heart surgery. Recommendations: A resistance exercise guidelines should be planned and offered on regular basis for patients undergoing cardiac surgery.
\end{abstract}

\section{Key Words: Pulmonary Function, Resistance Exercise \& Open Heart Surgery.}

\section{Introduction}

Resistance training is any physical activity that causes the muscles to work against an additional force or weight (this concept is called resistance). There are essentially two different types of resistance training exercises: by continually rebuilding muscles and enhances muscle strength, which protects joints and improves stability and balance, reducing the risk of falls.. regular resistance training will increase muscle and bone strength, as well as bone density, Resistance training programs designed for older adults, such as stay strong stay healthy (University of Missouri, Extension) also support a better quality of life by promoting independence and contributing to the maintenance of functional abilities

( Ball, et al., 2013).

Resistance Training Guidelines recommend the inclusion of resistance training for healthy persons of all ages, participate in moderate or high intensity resistance training two or more days a week. Children and adolescents are recommended to practice exercise at least three days a week ( U.S. Department of Health \& Human Services 2018). In 2011, the American College of Sports Medicine (ACSM) published research-based guidelines for resistance training using machine-based exercises and free weights (examples: dumbbells and barbells) (Garber ,et

exercise training Increases functional status and quality of life in COPD patients, The component strategies include exercise training, education, nutritional intervention and psychosocial support Pulmonary rehabilitation is a comprehensive intervention (GOLD Science Committee Members 2017).

resistance training can effectively increase muscle mass and enhance muscle strength and even reduce all-cause mortality in COPD patients, Loprinzi, et al., 2017) .

a program including resistance exercises and aerobic training is needed for the rehabilitation of COPD patients. Conventional exercise training usually conducted by various facilities, including treadmill, cycle ergometer, weight training machines, and other types of equipment, (Daabis, et al., 2017) \& (Boeselt, et al., 2017)

Pulmonary function tests (PFT's) are breathing tests to find out how well the patients move air in and out 
of them lungs and how well oxygen enters them body. The most common pulmonary function test 's are spirometry, diffusion studies and body plethysmography . Lung function tests can be used to: Compare the patients lung function with known standards that show how well them lungs should be working. , Measure the effect of exercise on lung function., Identify early changes in lung function that might show a need for a change in treatment, detect narrowing in the airways, decide if a medicine (such as a bronchodilator) could be helpful to use and determine your ability to tolerate surgery and medical procedures. (Graham, 2014).

The pulmonary function Measurement as forced vital capacity (FVC), forced expiratory volume in the first second (FEV1), forced expiratory coefficient in the first second (FEV1/ FVC [\%]) and peak expiratory flow (PEF) (Soltanifar, et al., 2019).

Postoperative care, including early mobilization, physiotherapy interventions and cardiac rehabilitation programs are aimed at supporting the recovery course following cardiac surgery and reducing the negative impact of surgery Even though an increased level of physical activity compared to preoperative, the study conducted previously presented positive effects in pulmonary function in more physically active cardiac surgery patients( Jonsson, et al., 2014).

The most common type of heart surgery is coronary artery bypass grafting (CABG) surgery is commonly performed via a median sternotomy. The surgical therapy is achieved by grafting a section of a saphenous vein, and / or internal mammary artery (IMA) between the aorta and the obstructed coronary artery distal to the obstructive lesion.(Favaloro, 2010).

Coronary artery bypass grafting $(\mathrm{CABG})$ is one of the most common operations, with more than 300,000 cases being performed annually in the United States alone (Nezafati, et al., 2017).

\section{Significance of the study}

From previous studies the Cardiac operation frequently are accompanied by post-operative pulmonary complications ( Konda et al., 2018).

Statistics in cardio thoracic care unit (CTCU) at South Valley University Hospital in year 2017 reported the number of patients admitted with open heart surgery, was 124,of them 60 or 70 patients with CABG (South Valley University Hospital Record, 2017).

This study could be beneficial in many ways; exercise is beneficial to all members of the body, especially the heart or blood vessels, where the sport activates the blood circulation through increasing the speed of the heart and the strength of constriction, also works on the expansion of the arteries of the body.

\begin{abstract}
Aim of the study
This study aimed to

-To investigate effect of early resistance exercise guidelines on pulmonary function measures of patients with open heart surgery.
\end{abstract}

\section{Research Hypotheses}

To fulfill the aim of the study the following research hypotheses are formulated:

- Open heart surgery Patient's who are exposed to Early Resistance Exercises guidelines less prone to increases length of hospital stay than patients who receive routine nursing care.

- Open heart surgery Patient's who are exposed to Early Resistance Exercises more prone to improve the pulmonary function measures than patients who receive routine nursing care.

\section{Research Design}

A quasi-experimental design was utilized in the present study.

Subjects: This study was included a convenient sample of 60 adult patients with open heart surgery from both sex assigned in to equal groups (control group and study group)

Setting: The study was conducted at the Cardio Thoracic intensive care unit (CTCU) at South valley University Hospital.

Tools of data collection

Tools: Three tools be used for data collection for this study.

\section{Tool 1: Patients assessment sheet}

This tool was developed by the researcher after reviewing of the relevant literature ((Smith et al, 2018) used to assess the studied patients regarding the - demographic data and medical related data as base line data, it includes two main parts as following.

Part one: Patient demographic and clinical data

It include demographic data (code, age, sex,) clinical data which include (length of hospital stay, past medical -surgical history, type of surgery,....etc.)

\section{Part two: Hemodynamic assessment tool:}

It included Vital signs (pulse rate $\mathrm{b} / \mathrm{m}$, respiratory rate $\mathrm{c} / \mathrm{m})$, mean arterial blood pressure MAP, and central venous pressure CVP).

Tool 2:- Pulmonary function measures:

The measures included forced vital capacity (FVC), forced expiratory volume in the first second (FEV1), forced expiratory coefficient in the first second (FEV1/ FVC [\%]), and peak expiratory flow (PEF), 
this tool adopted by (Soltanifar, et al., 2019) to measure pulmonary function.

- Tool 3: Borg scale "The Borg Rating of Perceived Exertion (RPE) scale, this tool adopted by Swedish researcher (Pageaux 2016), and has been used to measure the level of physical strain or perceived exertion. The Borg 15-point RPE scale a rating of 6 was to be associated with no exertion, i.e. rest, and a rating of 20 with maximal exertion, i.e. the most stressful exercise performed. Scoring system

\begin{tabular}{|c|c|}
\hline Number & items \\
\hline 6 & No exertion at all \\
\hline 7 & Extremely light \\
\hline 8 & - \\
\hline 9 & Very light \\
\hline 10 & - \\
\hline 11 & Light \\
\hline 12 & - \\
\hline 13 & Somewhat hard \\
\hline 14 & - \\
\hline 15 & Hard \\
\hline 16 & - \\
\hline 17 & Very hard \\
\hline 18 & Extremely hard \\
\hline 19 & Maximal exertion \\
\hline 20 & \\
\hline
\end{tabular}

Tool Validity

The developed tool 1 was tested for content validity by a jury of five specialists in the field of critical and emergency nursing and cardiology from Assiut University, and necessary modification were done.

Tool Reliability

The reliability was done on the developed tool 1 by Cronbach alpha test and reliability level was $(0,89)$. To assess the consistency and stability of the tool., tool 2 at reliability level was $(0.86)$ and tool 3 at reliability level was $(0.86)$.

\section{Pilot study}

After selected the tools, a pilot study was conducted on $10 \%$ of study subjects (Six patients). IT was conducted to test clarity, completeness and the time involvement. Results of the data collection tools illustrated that no any refinements and modifications needed so the patients were included to the actual study subjects..

\section{Ethical considerations}

1- Research proposal approved from Ethical Committee in the Faculty of Nursing

2- There was no risk for study subject during application of the research.

3- The study followed common ethical principles in clinical research.
4- Written consent obtained from patients or guidance that were willing to participate in the study after explaining the nature and purpose of the study

5- Patient assured that the data of this research not be refused without a second permission.

6- Confidentiality and anonymity assured.

7- Patients had the right to refuse to participate and lor withdraw from the studyl without any rationale at any time.

\section{Procedure}

Permission was initially obtained from the cardio thoracic ICU management committee to enable the study to be conducted in the selected unit. Permission was not only granted to conduct the study, but to assist with the recruitment of the participants. The south valley university's and Hospital ethics committees granted approval for the study to be conducted in the selected ICU.

The study was conducted through 3 phases: A assessment phase, Implementation phase \& Evaluation phase.

Assessment phase :-The researcher assessed the patients using tool 1 to collect demographic data (age, sex,), clinical data, hemodynamic assessment such as : Vital signs (pulse rate $\mathrm{b} / \mathrm{m}$, respiratory rate $\mathrm{c} / \mathrm{m}$, mean arterial blood pressure(MAP) and central venous pressure(CVP).

Using tools $2 \& 3$ assessed pulmonary function measure and rating of perceived exertion.

\section{Implementation phase}

Control group receive routine hospital care: early ambulation, deep breathing \& cough exercise.

Study group receive routine hospital care: early ambulation, deep breathing, cough exercise \& early resistance exercise guidelines. with dumbbell: -Post 6 hours of operation and then day after day until patient discharge, Frequency 2-3 times a week, Intensity 7exercises Set of 8-10 repetition for each exercise, Time30 minutes, twice a day and Type: Chest press, Biceps and triceps curls, Calf rises, Elbow flexion Knee extension, Hip adductors and Hip abductors

- The resistance exercise guidelines starts after 6 hours of separation of the patient from the mechanical ventilation.

- The researcher followed Personal protections technique.

- Place patient in comfort position.

- Assess patient condition before and after exercises.

- Assess and monitor hemodynamic parameters before and after every exercise.

- Measure effort and exertion for patient.

- The researcher explained early resistance exercises for each p.ts before implementation 
- Each patient received diaphragmatic breathing exercises, progressive ambulation and resistance exercises for upper limb and lower limb. Initial load was established using, which consisted of a set of 10 repetitions using $0.5 \mathrm{~kg}$ dumbbells for elbow flexion and knee extension. The load was defined by subjective perceived effort using Borg scale.

- Resistance exercises consisted of muscle training with dumbbells for upper limb (biceps and triceps) and shin pads for Lower Limb (quadriceps) with the patient in Fowler 45, during immediate post-operative period and subsequently sitting in bed with free lower limb allowing alternated and unilateral knee extension. Exercise of hip adductors and abductors and triceps sure occurred at ward, where patient was free to ambulate, and consisted of three sets of 10 repetitions for each muscle group. Early resistance exercises were performed right after extubation for 30 minutes, twice a day in the (ICU) until hospital discharge. -The researcher record heart and respiratory rates, and oxygen saturation were monitored. Before, during and after practicing exercises, blood pressure was measured using a digital sphygmomanometer.

\section{Evaluation phase}

- -The researcher evaluated the clinical data and hemodynamic assessment by (tool 1).

- To pulmonary function by (Tool 2)

- Measuring an individual's effort and exertion, breathlessness and fatigue during physical work (tool 3) for both groups.

\section{Statistical analysis}

The data were tested for normality using the Anderson-Darling test and for homogeneity variances prior to further statistical analysis. Categorical variables were described by number \& percent $(\mathrm{N}, \%)$, where continuous variables described by mean and standard deviation (Mean, SD). Chi-square test and fisher exact test used to compare between categorical variables where compare between continuous variables by t-test and ANOVA TEST. A two-tailed $\mathbf{p}<0.05$ was considered statistically significant. We are used person Correlation to Appear the Association between scores .All analyses were performed with the IBM SPSS 20.0 software. 


\section{Results}

Table (1): frequncy percentage of demographic, clinical, surgical and postoperative data, of both groups.

\begin{tabular}{|c|c|c|c|c|c|}
\hline \multirow{2}{*}{ Variable } & \multicolumn{2}{|c|}{$\operatorname{Study}(n=30)$} & \multicolumn{2}{|c|}{$\operatorname{control}(n=30)$} & \multirow[t]{2}{*}{$\mathrm{P}$.value } \\
\hline & No. & $\%$ & No. & $\%$ & \\
\hline \multicolumn{6}{|l|}{ age group } \\
\hline More than 40 years & 16 & 53.3 & 21 & 70.0 & \multirow{2}{*}{0.184} \\
\hline Less than 40 years & 14 & 46.7 & 9 & 30.0 & \\
\hline Mean \pm SD & \multicolumn{2}{|c|}{$42.5 \pm 7.01$} & \multicolumn{2}{|c|}{$45.27 \pm 16.07$} & 0.391 \\
\hline \multicolumn{6}{|l|}{ Gender } \\
\hline Male & 15 & 50.0 & 18 & 60.0 & \multirow{2}{*}{0.436} \\
\hline Female & 15 & 50.0 & 12 & 40.0 & \\
\hline \multicolumn{6}{|l|}{ Type of Surgery } \\
\hline $\mathrm{CABG}$ & 12 & 40.0 & 13 & 43.3 & \multirow{3}{*}{0.355} \\
\hline MVR & 16 & 53.3 & 17 & 56.7 & \\
\hline Valve replacement & 2 & 6.7 & 0 & 0.0 & \\
\hline \multicolumn{6}{|l|}{ Past medical history } \\
\hline Angina & 4 & 13.3 & 0 & 0.0 & \multirow{4}{*}{0.110} \\
\hline DM & 4 & 13.3 & 3 & 10.0 & \\
\hline Hypertension. & 2 & 6.7 & 2 & 6.7 & \\
\hline Hypertensive & 7 & 23.3 & 0 & 0.0 & \\
\hline \multicolumn{6}{|l|}{ Past Surgery history } \\
\hline Appendectomy & 11 & 36.7 & 12 & 40.0 & \multirow{3}{*}{0.233} \\
\hline chest Pain, mitral valve & 1 & 3.3 & 0 & 0.0 & \\
\hline Cholecystectomy & 2 & 6.7 & 0 & 0.0 & \\
\hline
\end{tabular}

Chi-square test Statistically

- independent t-test * Significant difference at p. value $<0.05$,

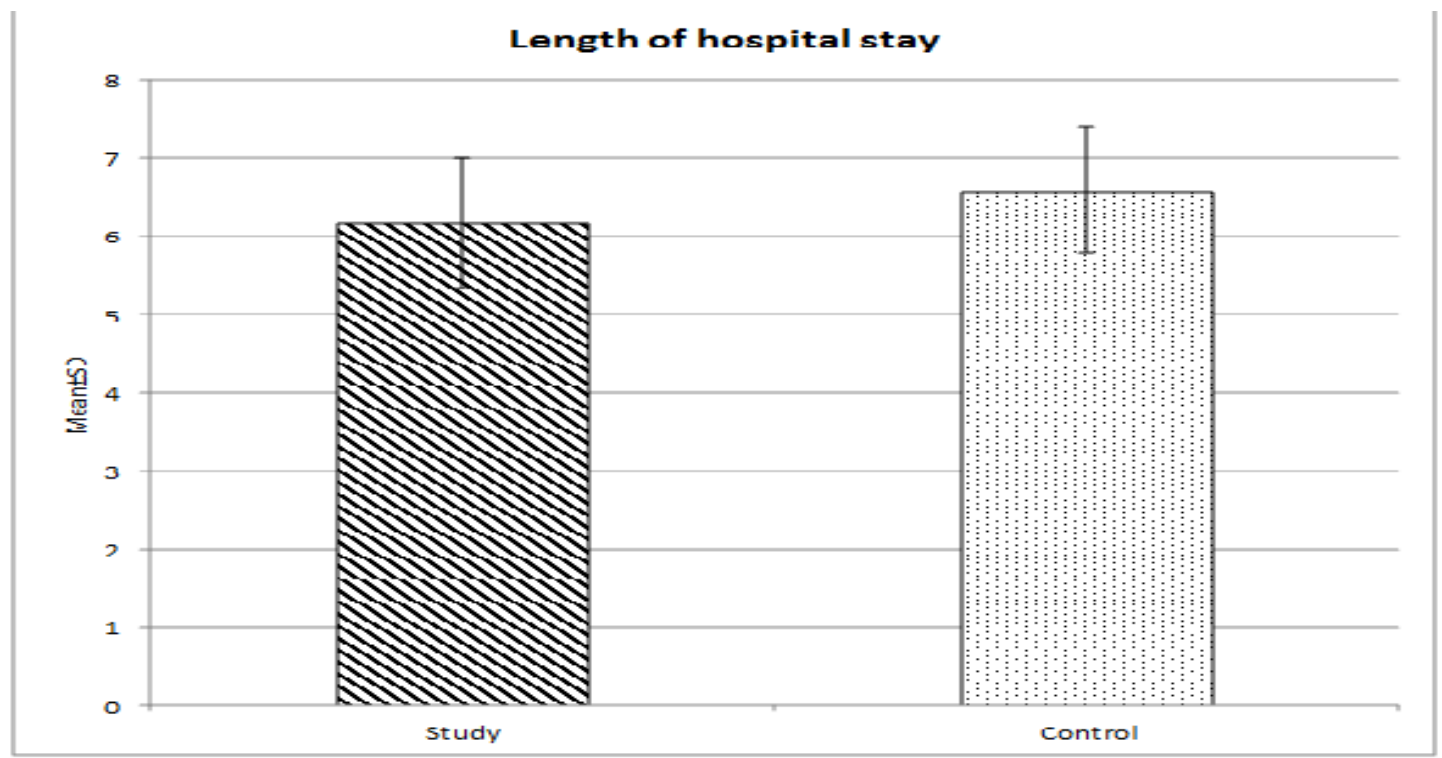

Fig (1) . Total Mean Scores for Length of hospital stay of patients with open heart surgery.

Chi-square test Statistically

- independent t-test $*$ Significant difference at p. value $<0.05$, 
Table (2): Comparison between the p.ts in Study and control group According to Hemodynamic Parameters Mean Scores.

\begin{tabular}{|c|c|c|c|}
\hline \multirow{2}{*}{ Hemodynamic Parameters } & study $(n=30)$ & control $(n=30)$ & \multirow{2}{*}{ P. value } \\
\hline & Mean \pm SD & Mean \pm SD & \\
\hline \multicolumn{4}{|l|}{ Pre Operation } \\
\hline Pulse & $82.4 \pm 8.91$ & $85.53 \pm 12.69$ & 0.273 \\
\hline respiratory rate & $18.93 \pm 2.69$ & $17.83 \pm 6.05$ & 0.367 \\
\hline Map & $95 \pm 6.05$ & $89.56 \pm 9.13$ & $0.009 * *$ \\
\hline CVP & $10.63 \pm 2.2$ & $9.5 \pm 2.19$ & $0.050 *$ \\
\hline \multicolumn{4}{|l|}{ Post Operation } \\
\hline Pulse & $83 \pm 7.93$ & $84 \pm 9.8$ & 0.666 \\
\hline respiratory Rate & $19.47 \pm 2.24$ & $19.63 \pm 4.72$ & 0.862 \\
\hline Мар & $95.23 \pm 5.03$ & $90.73 \pm 8.21$ & $0.013^{*}$ \\
\hline CVP & $10.03 \pm 1.16$ & $9.7 \pm 1.91$ & 0.418 \\
\hline \multicolumn{4}{|l|}{$3^{\text {rd day Pre }}$} \\
\hline Pulse & $80.33 \pm 5.4$ & $84.17 \pm 13.59$ & 0.156 \\
\hline respiratory Rate & $18.3 \pm 2.15$ & $20.3 \pm 4.09$ & $0.021 *$ \\
\hline Map & $92.73 \pm 6.35$ & $88.47 \pm 9.41$ & $0.044^{*}$ \\
\hline CVP & $9.3 \pm 1.74$ & $8.17 \pm 1.64$ & $0.012 *$ \\
\hline \multicolumn{4}{|l|}{$3^{\text {rd day Post }}$} \\
\hline Pulse & $85.03 \pm 5.44$ & $87.07 \pm 11.79$ & 0.394 \\
\hline respiratory Rate & $20.1 \pm 2.34$ & $21.2 \pm 3.65$ & 0.170 \\
\hline Map & $98.27 \pm 6.75$ & $95.23 \pm 8.64$ & 0.135 \\
\hline CVP & $10.03 \pm 1.79$ & $8.13 \pm 1.48$ & $<0.001 * *$ \\
\hline \multicolumn{4}{|l|}{$5^{\text {th }}$ day Pre } \\
\hline Pulse & $78.23 \pm 6.34$ & $78.73 \pm 12.04$ & 0.841 \\
\hline respiratory Rate & $18.83 \pm 2.04$ & $19.47 \pm 4.09$ & 0.451 \\
\hline Map & $95.43 \pm 5.61$ & $91.83 \pm 6.84$ & $0.030 *$ \\
\hline CVP & $8.23 \pm 1.55$ & $7.1 \pm 1.4$ & $0.004^{* *} *$ \\
\hline \multicolumn{4}{|l|}{$5^{\text {th }}$ day Post } \\
\hline Pulse & $83.63 \pm 6.43$ & $87 \pm 10.82$ & 0.148 \\
\hline respiratory Rate & $20.8 \pm 2.38$ & $20.27 \pm 2.64$ & 0.415 \\
\hline Map & $97.57 \pm 4.7$ & $95.09 \pm 5.97$ & 0.080 \\
\hline CVP & $9.23 \pm 1.33$ & $7.67 \pm 1.97$ & $0.001 * *$ \\
\hline \multicolumn{4}{|l|}{$7^{\text {th }}$ day pre } \\
\hline Pulse & $80.23 \pm 7.51$ & $81.07 \pm 23.24$ & 0.852 \\
\hline respiratory Rate & $19.33 \pm 1.21$ & $20.37 \pm 2.43$ & $0.041 *$ \\
\hline Map & $93.63 \pm 6.17$ & $92.03 \pm 6.3$ & 0.325 \\
\hline CVP & $7.67 \pm 1.49$ & $8.17 \pm 1.51$ & 0.202 \\
\hline \multicolumn{4}{|l|}{$7^{\text {th }}$ day Post } \\
\hline Pulse & $86.37 \pm 7.77$ & $87.97 \pm 7.1$ & 0.408 \\
\hline respiratory Rate & $22.13 \pm 2.19$ & $22.83 \pm 3.38$ & 0.346 \\
\hline Map & $97.33 \pm 5.37$ & $92.18 \pm 6.81$ & $0.002 * *$ \\
\hline CVP & $9.13 \pm 1.53$ & $7.8 \pm 1.35$ & $0.001 * *$ \\
\hline
\end{tabular}

- independent t-test $*$ Significant difference at p. value $<0.05, * *$ Significant difference at $p$. value $<0.01$ 
Table (3): Comparison between the p.ts in Study and control group According to Pulmonary Function measures.

\begin{tabular}{|c|c|c|c|}
\hline Pulmonary Function measures & Study & control & P.value \\
\hline \multicolumn{4}{|l|}{ Pre-Operative } \\
\hline forced vital capacity & $3.21 \pm 0.54$ & $3.07 \pm 0.72$ & 0.396 \\
\hline forced expiratory volume in the first second & $2.67 \pm 0.44$ & $2.55 \pm 0.57$ & 0.364 \\
\hline forced expiratory coefficient in the first second & $70.46 \pm 3.56$ & $72.09 \pm 5.72$ & 0.191 \\
\hline peak expiratory flow & $6.15 \pm 0.91$ & $5.21 \pm 1.19$ & $0.001 * *$ \\
\hline \multicolumn{4}{|l|}{$3^{\text {rd }}$ days } \\
\hline forced vital capacity & $2.75 \pm 0.46$ & $3.1 \pm 1.78$ & 0.300 \\
\hline forced expiratory volume in the first second & $3.24 \pm 0.52$ & $2.83 \pm 0.6$ & $0.010 *$ \\
\hline forced expiratory coefficient in the first second & $70.56 \pm 3.52$ & $69.76 \pm 3.61$ & 0.411 \\
\hline peak expiratory flow & $6.18 \pm 0.94$ & $5.18 \pm 1.4$ & $0.003 * *$ \\
\hline \multicolumn{4}{|l|}{$5^{\text {th }}$ day } \\
\hline forced vital capacity & $3.44 \pm 0.96$ & $2.89 \pm 0.7$ & $0.024 *$ \\
\hline forced expiratory volume in the first second & $2.77 \pm 0.4$ & $2.41 \pm 0.45$ & $0.003 * *$ \\
\hline forced expiratory coefficient in the first second & $70.72 \pm 3.67$ & $70.59 \pm 3.76$ & 0.896 \\
\hline peak expiratory flow & $6.17 \pm 0.95$ & $5.21 \pm 1.39$ & $0.004 * *$ \\
\hline \multicolumn{4}{|l|}{$7^{\text {th }}$ day } \\
\hline forced vital capacity & $3.31 \pm 0.52$ & $2.98 \pm 0.75$ & 0.066 \\
\hline forced expiratory volume in the first second & $2.75 \pm 0.43$ & $2.58 \pm 0.59$ & 0.227 \\
\hline forced expiratory coefficient in the first second & $70.75 \pm 3.67$ & $70.89 \pm 3.48$ & 0.882 \\
\hline peak expiratory flow & $6.23 \pm 0.92$ & $5.29 \pm 1.36$ & $0.004 * *$ \\
\hline \multicolumn{4}{|l|}{ On- discharge } \\
\hline forced vital capacity & $3.38 \pm 0.51$ & $3.18 \pm 0.84$ & 0.269 \\
\hline forced expiratory volume in the first second & $2.79 \pm 0.43$ & $2.75 \pm 0.68$ & 0.752 \\
\hline forced expiratory coefficient in the first second & $70.84 \pm 3.84$ & $65.31 \pm 22.26$ & 0.185 \\
\hline peak expiratory flow & $6.29 \pm 0.92$ & $5.31 \pm 1.47$ & $0.003 * *$ \\
\hline
\end{tabular}

- independent t-test $*$ Significant difference at p. value $<0.05, * *$ Significant difference at p. value $<0.01$

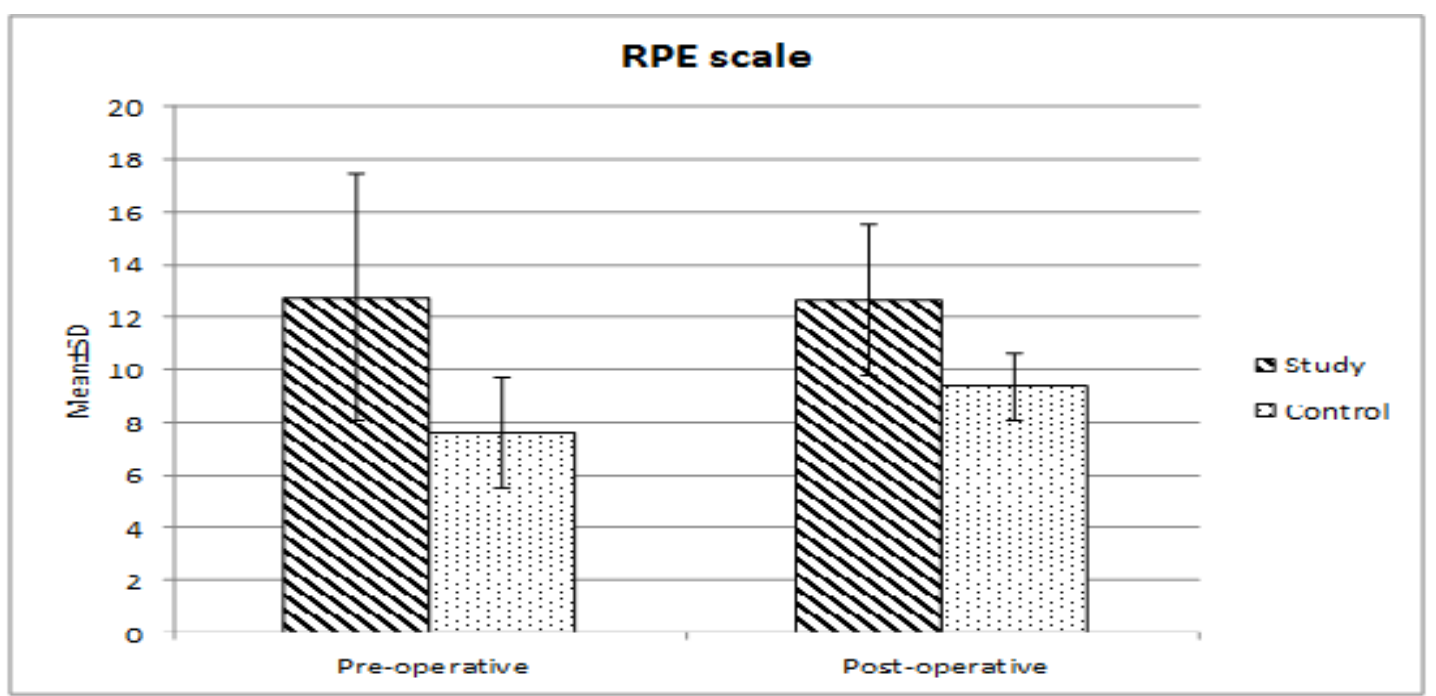

Fig (2): Comparison Total Mean Scores between Study and control group According to (Rating of Perceived Exertion) scale during pre and Post-operative.

- Chi-square test Statistically *Significant difference at P. value $<0.05$, **Significant difference at P. value $<0.01$

- independent t-test $* *$ Significant difference at p. value $<0.01$. 
Table (4): Comparison between the p.ts in Study and control group according to (Rating of Perceived Exertion) scale (Pre, during and post) Exercise.

\begin{tabular}{|c|c|c|c|c|c|c|c|c|c|c|c|c|c|c|c|}
\hline \multirow{3}{*}{ RPE Scale } & \multicolumn{5}{|c|}{ Pre } & \multicolumn{5}{|c|}{ During } & \multicolumn{5}{|c|}{ After } \\
\hline & \multicolumn{2}{|c|}{ Study } & \multicolumn{2}{|c|}{ Control } & \multirow{2}{*}{ P.value } & \multicolumn{2}{|c|}{ study } & \multicolumn{2}{|c|}{ control } & \multirow{2}{*}{ P.value } & \multicolumn{2}{|c|}{ Study } & \multicolumn{2}{|c|}{ Control } & \multirow{2}{*}{ P.value } \\
\hline & No & $\%$ & No & $\%$ & & No & $\%$ & No & $\%$ & & No & $\%$ & No & $\%$ & \\
\hline \multicolumn{16}{|l|}{$3^{\text {rd }}$ day } \\
\hline $\begin{array}{l}\text { No } \\
\text { exeration } \\
\text { at all }\end{array}$ & 10 & 33.3 & 20 & 71.4 & \multirow{6}{*}{$0.013 *$} & 0 & 0.0 & 0 & 0.0 & \multirow{6}{*}{0.410} & 8 & 26.7 & 0 & 0.0 & \multirow{6}{*}{$<0.001^{* * *}$} \\
\hline $\begin{array}{l}\text { Extremely } \\
\text { Light }\end{array}$ & 4 & 13.3 & 3 & 10.7 & & 6 & 20.0 & 3 & 10.7 & & 10 & 33.3 & 0 & 0.0 & \\
\hline very light & 2 & 6.7 & 2 & 7.1 & & 11 & 36.7 & 17 & 60.7 & & 10 & 33.3 & 8 & 32.0 & \\
\hline Light & 3 & 10.0 & 3 & 10.7 & & 9 & 30.0 & 6 & 21.4 & & 2 & 6.7 & 17 & 68.0 & \\
\hline $\begin{array}{l}\text { Somewhat } \\
\text { hard }\end{array}$ & 4 & 13.3 & 0 & 0.0 & & 4 & 13.3 & 4 & 14.3 & & Heavy & 0.0 & 0 & 0.0 & \\
\hline Heavy & 7 & 23.3 & 0 & 0.0 & & 0 & 0.0 & 0 & 0.0 & & 0 & 0.0 & 0 & 0.0 & \\
\hline Mean \pm SD & \multicolumn{2}{|c|}{$10 \pm 3.75$} & \multicolumn{2}{|c|}{$6.91 \pm 1.68$} & $<0.001 * *$ & \multicolumn{2}{|c|}{$9.93 \pm 1.88$} & \multicolumn{2}{|c|}{$9.88 \pm 1.73$} & 0.915 & \multicolumn{2}{|c|}{$9.75 \pm 1.8$} & \multicolumn{2}{|c|}{$12.52 \pm 0.96$} & $<0.001 * *$ \\
\hline \multicolumn{16}{|l|}{ 5th day } \\
\hline $\begin{array}{l}\text { No } \\
\text { exeration } \\
\text { at all }\end{array}$ & 4 & 13.3 & 8 & 32.0 & \multirow{6}{*}{$0.035^{*}$} & 3 & 10.0 & 0 & 0.0 & \multirow{5}{*}{$0.017 *$} & 7 & 23.3 & 0 & 0.0 & \multirow{6}{*}{$0.003 * *$} \\
\hline $\begin{array}{l}\text { Extremely } \\
\text { Light }\end{array}$ & 8 & 26.7 & 12 & 48.0 & & 10 & 33.3 & 5 & 17.9 & & 10 & 33.3 & 3 & 12.0 & \\
\hline very light & 5 & 16.7 & 2 & 8.0 & & 14 & 46.7 & 10 & 35.7 & & 2 & 6.7 & 4 & 16.0 & \\
\hline Light & 8 & 26.7 & 3 & 12.0 & & 3 & 10.0 & 10 & 35.7 & & 6 & 20.0 & 2 & 8.0 & \\
\hline $\begin{array}{l}\text { Somewhat } \\
\text { hard }\end{array}$ & 5 & 16.7 & 0 & 0.0 & & 0 & 0.0 & 3 & 10.7 & & 5 & 16.7 & 11 & 44.0 & \\
\hline Heavy & 0 & 0.0 & 0 & 0.0 & & 0 & 0.0 & 0 & 0.0 & & 0 & 0.0 & 3 & 12.0 & \\
\hline Mean \pm SD & 9.57 & \pm 2.42 & 7.6 & \pm 1.48 & $0.001 * *$ & 8.72 & \pm 1.36 & 10.0 & +1.68 & $0.001 * *$ & $9.17=$ & 2.6 & 12.1 & \pm 2.47 & $<0.001 * *$ \\
\hline 7th day & & & & & & & & & & & & & & & \\
\hline $\begin{array}{l}\text { No } \\
\text { exeration } \\
\text { at all }\end{array}$ & 11 & 36.7 & 8 & 28.6 & & 0 & 0.0 & 0 & 0.0 & & 22 & 73.3 & 0 & 0.0 & \\
\hline $\begin{array}{l}\text { Extremely } \\
\text { Light }\end{array}$ & 4 & 13.3 & 10 & 35.7 & & 20 & 66.7 & 3 & 10.7 & & 0 & 0.0 & 3 & 15.8 & \\
\hline very light & 10 & 33.3 & 5 & 17.9 & 0.282 & 8 & 26.7 & 8 & 28.6 & $0.000 * *$ & 4 & 13.3 & 3 & 15.8 & คดคด** \\
\hline Light & 3 & 10.0 & 2 & 7.1 & & 2 & 6.7 & 4 & 14.3 & & 2 & 6.7 & 3 & 15.8 & 0.000 \\
\hline $\begin{array}{l}\text { Somewhat } \\
\text { hard }\end{array}$ & 2 & 6.7 & 3 & 10.7 & & 0 & 0.0 & 10 & 35.7 & & 2 & 6.7 & 4 & 21.1 & \\
\hline Heavy & 0 & 0.0 & 0 & 0.0 & & 0 & 0.0 & 3 & 10.7 & & 0 & 0.0 & 0 & 0.0 & \\
\hline $\begin{array}{l}\text { Etermly } \\
\text { hard }\end{array}$ & 0 & 0.0 & 0 & 0.0 & & 0 & 0.0 & 0 & 0.0 & & 0 & 0.0 & 3 & 15.8 & \\
\hline $\begin{array}{l}\text { Maximal } \\
\text { exeration }\end{array}$ & 0 & 0.0 & 0 & 0.0 & & 0 & 0.0 & 0 & 0.0 & & 0 & 0.0 & 3 & 15.8 & \\
\hline Mean \pm SD & 8.37 & \pm 2.07 & & \pm 2.2 & 0.811 & 8.3 & 1.06 & 11.3 & \pm 2.33 & $0.000 * *$ & $7.43 \pm$ & 2.21 & 13.2 & \pm 4.74 & $0.000^{* *}$ \\
\hline
\end{tabular}

- independent t-test * Significant difference at p. value $<0.05$, ** Significant difference at p. value <0.01.

Table (I): Presents a comparison the population characteristics between the Study and the control groups. No statistically significant differences could be Detected between the two groups as regards toage,sex,type of surgery, past medical history and past surgery history. $(\mathrm{P}=0.184,0.391,0.436,0.355,0.110$ and 0.233 respectively). 
Figure (1): Presents total mean scores for length of hospital stay of patients with open heart surgery An decrease in the mean scores in the study group was observed at $(6.17 \pm 0.83)$ compared with control group $(6.6 \pm 0.81$. with a statistical significant difference $(P$. $0.019)$.

Table (2): Illustrates that there were a significant differences in Hemodynamic Parameters in preoperative period between the study and the control groups there were a significant variations in the mean scores of mean arterial blood pressure MAP in study group has higher mean scores $(95 \pm 6.05)$ compared with mean of control group $(89.56 \pm 9.13)$ with a statistical significant difference (P. 0.009) .

Illustrates that there were a significant differences in Hemodynamic Parameters in 3rd day post period between the study and the control groups there were a significant variations in the mean scores of central venous pressure CVP in study group has higher mean scores $(10.03 \pm 1.79)$ compared with mean of control group $(8.13 \pm 1.48)$ with a very highly significant difference (p. <0.001)

Illustrates that there were a significant differences in Hemodynamic Parameters in 5th day post period between the study and the control groups that there were a significant differences in central venous pressure CVP in study group has higher mean scores $(9.23 \pm 1.33)$ compared with mean of control group $(7.67 \pm 1.97)$ with a statistical significant difference (P. 0.001).

Table (3): Presents total mean scores of pulmonary function measures There was an obvious increase in preoperative period in the total mean scores of Peak expiratory flow (PEF) in study group when compared with control group $(6.15 \pm 0.91,5.21 \pm 1.19)$ respectively with a very highly significant difference (p0.001).

Presents that there were a significant differences in pulmonary function measures there were a significant variations in the mean scores of Peak expiratory flow (PEF)study group has higher mean scores(6.18 \pm 0.94$)$ compared with mean of control group $(5.18 \pm 1.4)$ with a statistical significant difference in $3^{\text {rd }}$ day (P.0.003).

Fig (2): Show the difference between the total mean scores of Study and control group According to (Rating of Perceived Exertion) scale during pre and Post-operative an significant variations in the mean scores study group has higher mean scores pre $(12.77 \pm 4.71)$, post $(12.67 \pm 2.88)$ compared with mean of control group pre $(7.6 \pm 2.09)$, post $(9.36 \pm 1.27)$ with a statistical significant difference in on discharge $(\mathrm{P}<0.001)$.

Table (4): Demonstrates the comparison of total mean score between the study and the control groups in the According to Rating of Perceived Exertion (RPE) scale (Pre, during and post) Exercise. there were a significant differences in Rating of Perceived Exertion (RPE) scale a significant variations in the mean scores of study group has lower mean scores during and post $7^{\text {th }}$ day exercise $(8.3 \pm 1.06,7.43 \pm 2.21)$ compared with mean of control group $(11.32 \pm 2.33$, $13.24 \pm 4.74)$ with a very highly statistical significant difference(P.0.000).

\section{Discussion}

The main challenge for the critical care nurse is caring for p.ts with open heart surgery. They develops several postoperative complications that may prolong postoperative recovery. Many of these were said to be prevented by early activity which is one of the many nurses' duties (Smith et al., 2018)

In the present sample, no statistically significant differences were found between study and control groups concerning the population characteristics. This demonstrates the homogeneity of the two selected groups; therefore any difference between them can be referred only to the applied regime of study group.

The present study showed a significant improvement of the patients' outcome including pulmonary functions and cardiovascular stability that lead to rapid recovery and early discharge (Zhang et al., 2018)

This might be referred to decrease in the length of stay in ICU among the study group. Several results reported such finding (Canfield \& Udeh 2019).

In the present study mean arterial blood pressure (MAP) increased in the study group and decreased in the control group pre \& post-operative, Both parameters returned almost to the preoperative values on $7^{\text {th }}$ day after operation. No difference could be detected between the study and the control groups in pulse rate. Nor turning the Patient affected the hemodynamic stability. However, another study reported an increase in both central venous pressure and mean arterial blood pressure during ambulation and stair climbing (Ahmed, 2019). Several studies have investigated the increases in cardiac stroke volume and heart rate raise cardiac output, which coupled with a transient increase in systemic vascular resistance, elevate mean arterial blood pressure. However, long-term exercise can promote a net reduction in blood pressure at rest. A meta-analysis of randomized controlled interventional studies found that regular moderate to intense exercise performed 3-5 times per week lowers blood pressure by an average of 3.4/2.4 mmHg (Nystoriak, \& Bhatnagar, 2018). 
The postoperative changes in pulmonary function may be important for patients with pre-existing pulmonary diseases or those undergoing future thoracic surgery. Further studies are needed to identify possible risk factors for the development of long-term postoperative changes in pulmonary function after cardiac surgery. There is also a need for studies investigating the clinical relevance of the reduction of pulmonary function, as well as studies evaluating postoperative pulmonary management in the long-term perspective after cardiac surgery .

The patients received basic postoperative chest physiotherapy as conventionally used at the Department of Cardiothoracic Surgery including early mobilization and deep breathing exercises during the first postoperative days, and cardiac rehabilitation offered to most patients postoperatively. No method of postoperative pulmonary therapy has been distinguished as superior in preventing or treating long-term changes in pulmonary function after cardiac surgery and clinical practice varies regarding recommendations on therapy after discharge this finding is somewhat agreed with that of (Westerdahl, et al., 2014)

Decreased length of hospitalization for cardiac surgery patients poses challenges to the possibilities of providing interventions that will facilitate optimal recovery. Physical activity is beneficial in both the prevention and treatment of patients with ischemic heart disease, and patients undergoing $C A B G$ have demonstrated improved functional capacity 2 years after These results concur with those of; (Nery et al., 2010). We have previously presented positive effects in pulmonary function in more physically active cardiac surgery patients. These results are in agreement with those of (Jonsson, et al., 2014).

In the present study, revealed to the resistance exercises did demonstrate a significant improvement in pulmonary function test parameter(FVC, FEV1, FEV1/ FVC and PEF)in study group postoperatively, These findings are in an agreement with Han \& Kim, (2018) \& Mustafaoglu et al., (2019)who found that the use of upper body resistance training is novel in its use of improving pulmonary function and more specifically spirometry parameters. The present study succeeded in significantly increasing in respiratory muscle strength and muscle endurance, effectively achieving an improved respiratory muscle function and performance in selected spirometry parameters. Roldán et al., (2019) also demonstrated that gravity resistance exercise and neuromuscular facilitation of the upper body did not increases some pulmonary function (i,e FEV1).
In this study the Rating of perceived exertion (RPE) for study group increase than control group at pre and post-operative.

- At5th day after operation showed significant increases in RPE pre exercise period $(\mathrm{p}=0.001)$ there was significant decrease in study group in RPE during and after exercise period than control group $(\mathrm{p}=0.001,<0.001)$.

At $7^{\text {th }}$ day after operation No significant differences could be found between the two groups in pre exercise period in RPE $(\mathrm{p}=0.811)$ however the study group significant decrease in RPE during and after exercise period than control group $(\mathrm{p}=0.000)$ From previous results it was found that resistance exercises improved the rating of perceived exertion scale.

Several studies have investigated the differences in RPE during resistance exercise between older and younger people. These studies found that the perceived exertion level during the same resistance exercise was significantly greater in older than in younger adults these results are consistent with those of (Pincivero, 2011).

it was concluded that patient's in control group with open heart surgery were lacking the good pulmonary function. Implementation of the resistance exercise guidelines was associated with significant improvements of pulmonary function measures, while also assisting in improving respiratory rate. Hemodynamic parameters thus leading to rapid recovery rate and reduction in length of hospital stay for study group and in general the guidelines achieved the aims for which it was conducted .

\section{Conclusion}

It can be concluded that The Resistance Exercise guidelines had a significant improvement on Pulmonary Function Measures of Patients with open heart surgery.

\section{Recommendations}

1. Based on the finding of the present study the following are recommended: 1-A resistance exercise training program should be planned and offered on regular basis for patients undergoing cardiac surgery.

2. 2- Using scientific evidence and expert opinion, the American Heart Association, with endorsement of the American College of Sports Medicine, has promulgated RT guidelines for individuals with and without $\mathrm{CV}$ disease.

3. 3-The training program for those without $\mathrm{CV}$ disease are Summarized briefly here in. resistance exercise is recommended a minimum of 2 days per week, with progression to 3 days per week. A 
typical workout should consist of 8 to 10 exercises to cover the major muscle groups, which includes the chest, shoulders, arms, back, abdomen, thighs, and lower leg

\section{Reference}

1. Ahmed, H., (2019): The Effect of Early Ambulation on Hemodynamic and Perfusion Indices Post Cardiac Surgery. American Journal of Nursing, 7(4), 490-498.

2. Ball S., (2013): Outcomes of Stay Strong, Stay Healthy in community settings. Journal of Aging and Health; 25(8):1388- 1397.

3. Boeselt, T., Nell, C., Lütteken, L., Kehr, K., Koepke, J., Apelt, S., \& Vogelmeier, C., (2017): Benefits of high-intensity exercise training to patients with chronic obstructive pulmonary disease: a controlled study. Respiration, 93(5), 301-310.

4. Canfield, C., \& Udeh, C., (2019): 1253: Teleicu Intensity Of Service Association With Decreased Icu Length Of Stay. Critical Care Medicine, 47(1), 603.

5. Daabis, R., Hassan, M., \& Zidan, M., (2017). Endurance and strength training in pulmonary rehabilitation for COPD patients. Egyptian Journal of Chest Diseases and Tuberculosis, 66(2), 231-236

6. Favaloro R., (2010): surgicaltreatment ofcoronaryarteriosclerosis.Baltimore:Williams\& Wilkins;325-357.

7. Garber C., (2011): American College of Sports Medicine position stand. Quantity and quality of exercise for developing and maintaining cardiorespiratory, musculoskeletal, and neuromotor fitness in apparently healthy adults: guidance for prescribing exercise. Medicine \& Science in Sports and Exercise. 43(7):13341359.

8. GOLD Science Committee Members (2017): The Global Strategy for the Diagnosis, Management and Prevention of COPD, Global Initiative

for Chronic Obstructive Lung Disease (GOLD) $2017 . \quad$ Retrieved from http///goldcopd.org.

9. Graham, B., (2014): Pulmonary Function Tests. American journal of respiratory and critical care medicine, 189(10), P17.

10. Han, J., \& Kim, Y., (2018): Effect of breathing exercises combined with dynamic upper extremity exercises on the pulmonary function of young adults. Journal of back and musculoskeletal rehabilitation, 31(2),405-409.
11. Jonsson M., Urell C., Emtner M., Westerdahl E., (2014): Self-reported physical activity and lung function two months after cardiac surgerya prospective cohort study. J Cardiothorac Surg.;9:59.

12. Konda, S., Ramsay, M., \& Madden, B., (2018): Respiratory Disease. Core Topics in Preoperative Anaesthetic Assessment and Management, 68.

13. Loprinzi, P., Sng, E., \& Walker, J., (2017): Muscle strengthening activity associates with reduced all-cause mortality in COPD. Chronic illness, 1 3(2), 140-147.

14. Mustafaoglu, R., Demir, R., Demirci, A., \& Yigit, Z., (2019): Effects of core stabilization exercises on pulmonary function, respiratory muscle strength, and functional capacity in adolescents with substance use disorder: Randomized controlled trial. Pediatric pulmonology.2-6.

15. Nery R., Martini M., Vidor C., Mahmud M., Zanini M., Loureiro A., Barbisan J., (2010): Changes in functional capacity of patients two years after coronary artery bypass grafting surgery. Rev Bras Cir Cardiovasc.;25:224-8.

16. Nezafati P., Kahrom M., Nezafati M., (2017): Endoscopic vein harvesting: the growing role in cardiac surgery. Arch Med Sci Atheroscler Dis 2:e34-6.

17. Nystoriak, M., \& Bhatnagar, A., (2018): Cardiovascular effects and benefits of exercise. Frontiers in cardiovascular medicine, 5, 135.

18. Pageaux, B., (2016): Perception of effort in exercise science: definition, measurement and perspectives. European Journal of Sport Science, 16(8), 885-894.

19. Pincivero D., (2011): Older adults underestimate RPE and knee extensor

20. Potter P, Perry A. Basic nursing: A critical thinking approach. St Louis: ed). Baltimore McGraw-Hill. pp.88-92. Preliminary report. American Surgeon. 1998; 64: 942-6.

21. Roldán, A., Cordellat, A., Monteagudo, P., García-Lucerga, C., Blasco-Lafarga, N., Gomez-Cabrera, M., \& Blasco-Lafarga, C., (2019): Beneficial Effects of Inspiratory Muscle Training Combined With Multicomponent Training in Elderly Active Women. Research Quarterly for Exercise and Sport, 1-8.

22. Smith, B., \& Field, L., (2018): Nursing Care: An essential guide for nurses and healthcare workers in primary and secondary care. Routledge.

23. Soltanifar, M., Karunanayake, C., Khadka, D., Henderson, R., \& Konehnck, N., (2019): 
Is A Body Shape Index (ABSI) Predictive of Lung Functions. Int J Respir Pulm Med, 6, 101.

24. South Valley University Hospital record, (2017).

25. US Department of Health and Human Services. (2018): Physical activity guidelines for Americans: be active, healthy, and happy!. http://www. health. gov/paguidelines/guidelines/default. Aspx

26. Westerdahl E., Urell C., Jonsson M., Bryngelsson I., Hedenstrom H., Emtner M., (2014): Deep breathing exercises performed 2 months following cardiac surgery: a randomized controlled trial. J Cardiopulm Rehabil Prev;34:34-42.

27. Zhang, Li, M., Gan, T., Qin, G., Wang, L., Zhu, M., \& Chen, X., (2018): Enhanced recovery after surgery pathway for patients undergoing cardiac surgery: a randomized clinical trial. European Journal of CardioThoracic Surgery, 54(3), 491-497. 